\title{
Syria: public health disasters in the era of no world order
}

\author{
Wasim Maziak $^{1}$
}

Received: 13 February 2018/Revised: 16 February 2018 / Accepted: 16 February 2018 / Published online: 20 February 2018

(C) Swiss School of Public Health (SSPH+) 2018

Syria used to be a small peaceful country of 23 million. It is on this land that humanity first learned the basics of civilized association, witnessed the birth of the first alphabet, and cultivated the world's main religions. Today, Syria is very sick, and the sickness is engulfing the people, history, and thousands of years of coexistence of cultures. Syria's health calamity was a direct result of the ongoing war, but also of failure of the international system for peace and security.

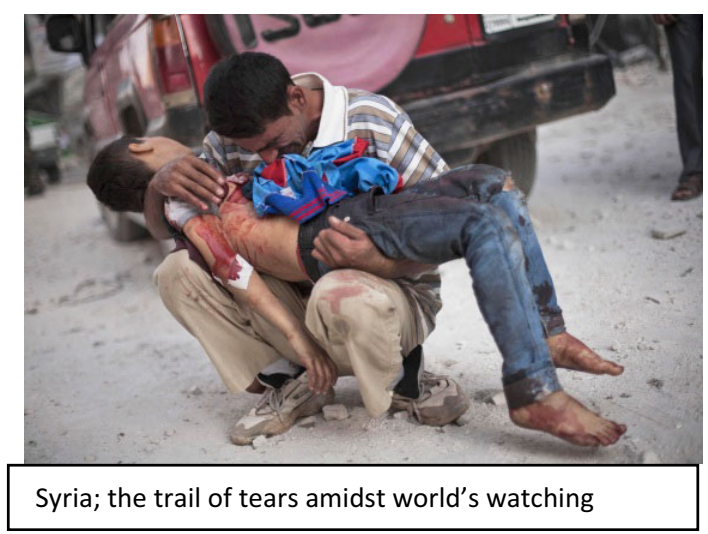

By the end of 2017, it is believed that about 12.8 million Syrians are in need of medical assistance, and 5.6 million in need of humanitarian assistance (Devi 2018). With sanitation, electricity, and clean water systems all affected by the war, the threat of large-scale epidemics, famine, and continued refugees outflow became a reality. Credible evidence documented outbreaks of typhoid fever, hepatitis, leishmaniasis, measles, tuberculosis, and the old scourge of polio in Syria (Ismail et al. 2016). Famine is not only threatening people in besieged areas but is used by the Syrian regime as a war strategy to force the surrender of hard-held resistance areas, as recently witnessed in Eastern

Wasim Maziak

wmaziak@fiu.edu

1 Department of Epidemiology, Florida International University, 11200 SW 8th St., Miami, FL 33139, USA
Ghouta. As war continues, the sick, old, and disabled citizens are forced to leave their homes, creating an everneedier refugees population.

One of the first victims of the Syrian war has been the breakdown of healthcare services. As the war deepened, most physicians fled the country leaving the majority of healthcare facilities either understaffed or closed (Taleb et al. 2015). Targeting of health care facilities and workers, moreover, has been a signature strategy of the Syrian regime and its Russian allies. Their targeting continues unabated amidst talks for a political solution, or even in the aftermath of Security Council's (SC) resolutions condemning them (Syrian American Medical Society; SAMS 2017). Dangers associated with seeking health care, and medications' high prices and unavailability not only affected those directly injured but more so many patients with chronic diseases. Many of those are old and disabled citizens with no one to turn to, not only for medical needs but for day-to-day life essentials.

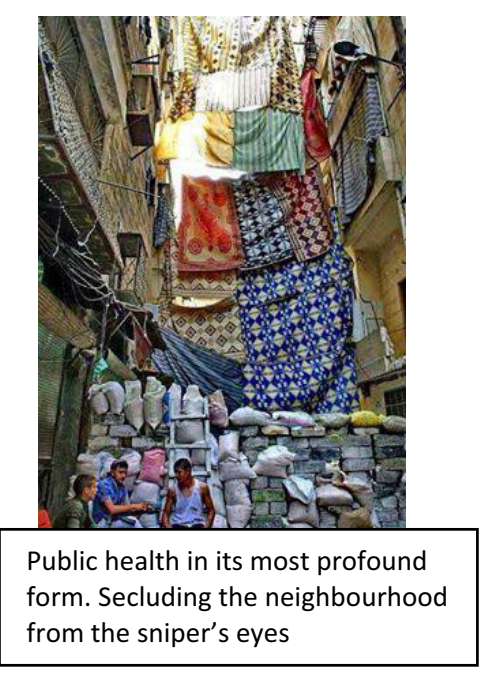

Internationally, the world system for peace architected by the victors of World War II and represented by the United Nations (UN) and Security Council (SC), failed miserably the Syrian people. What is more concerning is 
that such failure seems organic to UN-SC makeup, hence will likely to repeat every time we have a similar conflict. Such system favors members' acting in their own national interests rather than international peace. Syria is a prime example, where antagonism among SC members-Russia and their Western counterparts-has severely hampered the passing of most stripped-down resolutions. Regional bodies, such as the League of Arab Nations (LAN) suffered from the same ineptitude. Dominated by traditional sociopolitical structures, and lacking a clear strategy for regional peace, influential LAN members quickly aligned themselves along religious-sectarian lines of the Syrian war further igniting it instead of mediating for peace.

The political gridlock in Syria has also prevented humanitarian assistance, where the breakdown of ceasefires became the rule rather the exception. On the other hand, SC resolutions insisting on allowing aid still depended on approval from the fighting factions. Local partners for UN organizations were selected by the Syrian government, some of which were directly affiliated with the Assad family (Sparrow 2017). The recent "UN-sponsored" agreement on de-escalation zones did not hold much water without an effective mechanism for enforcement. In the words of Jan Egeland, the special UN advisor on Syria about Eastern Ghouta "there is only escalation in this deescalation zone" (Devi 2018). In the end, the dependency of humanitarian aid on fighting factions and their outside sponsors consistently restricted humanitarian space for civilians who were caught in the middle.

The enormous human and health toll of the Syrian war made the issue of providing medical assistance a top priority. At the end of 2016, only one partially operational facility had remained to tend to Eastern Aleppo's quarter million inhabitants. As the UN main organization for health, the World Health Organization (WHO) charter states that it provides assistance only at the request and with the approval of national governments. This has greatly limited WHO's ability to function in situations where the national government is a party in the conflict and has led to differential response to the detriment of the areas controlled by the opposition. In contrast, independent health organizations (e.g. SAMS, Médecins Sans Frontières') had more freedom, which allowed them to be the main actors in opposition-controlled areas. These organizations have the advantage of less red tape, faster response rate, and a simpler organizational structure and hierarchy.

The human catastrophe of Syria is a result of the failure of the international system for peace and humanitarian assistance, which favors the interests of international powerhouses over the wellbeing of those affected by war. The flood of pleas from civilians caught in this prolonged tragedy continues to fall on the deaf ear of the international community, exemplifying how the Syrian war exposed the all-out disregard of any standard in dealing with mass human suffering. As conflicts become complex and humanitarian crises protracted, a rethinking of the humanitarian and peacekeeping landscape is needed.

\section{Compliance with ethical standards}

Conflict of interest The author declares that he has no competing interests.

\section{References}

Devi S (2018) Syria: 7 years into a civil war. Lancet 391(10115):15-16. https://doi.org/10.1016/S0140-6736(18)30006-0

Ismail SA, Abbara A, Collin SM et al (2016) Communicable disease surveillance and control in the context of conflict and mass displacement in Syria. Int J Infect Dis 47:15-22. https://doi.org/ 10.1016/j.ijid.2016.05.011

Sparrow A (2017) Enabling Assad: the UN's failure in Syria. Foreign Affairs. https://www.foreignaffairs.com/articles/syria/2017-0111/enabling-assad. Accessed 20 Dec 2017

Syrian American Medical Society (2017) The failure of UN Security Council Resolution 2286 in preventing attacks on healthcare in Syria. https://foundation.sams-usa.net/wp-content/uploads/2017/ 01/SAMS-2286-Report.pdf. Accessed 27 Jan 2018

Taleb ZB, Bahelah R, Fouad FM et al (2015) Syria: health in a country undergoing tragic transition. Int $\mathrm{J}$ Public Health 60:63-72. https://doi.org/10.1007/s00038-014-0586-2 